\title{
A STUDY OF EFFECT OF WAIST-TO-HIP RATIO ON CARDIORESPIRATORY FITNESS IN YOUNG HEALTHY MALES
}

Vivek $\mathrm{P}^{1}$, Thejaswini K.O², Kavitha B.S ${ }^{3}$

\section{HOW TO CITE THIS ARTICLE:}

Vivek P, Thejaswini KO, Kavitha BS. "A study of effect of waist-to-hip ratio on cardiorespiratory fitness in young healthy males". Journal of Evolution of Medical and Dental Sciences 2013; Vol2, Issue 40, October 30; Page: 7658-7663.

ABSTRACT: BACKGROUND: Low cardiorespiratory fitness in young male adults has emerged as an important factor for developing cardiovascular comorbidities later in middle age. Increased body fatness as predicted by waist-to-hip ratio is an additional factor for developing cardiovascular diseases. AIMS: To determine the cardiorespiratory fitness in terms of $\mathrm{VO}_{2}$ max by Queen's college step test in young male subjects. To study the relation between waist to hip ratio and cardiorespiratory fitness. METHODS: One hundred young healthy male subjects in the age group of 18 to 25 years were included in this study group. Waist-to-hip ratio (WHR) was measured using standard calibrated instruments. Cardiorespiratory fitness in terms of $\mathrm{VO}_{2}$ max was assessed by following the protocol of Queen's College Step Test (QCT). RESULTS: Data was statistically analysed by using Pearson's correlation. There was a significant negative correlation between Waist-to-hip ratio and $\mathrm{VO}_{2} \max (\mathrm{ml} / \mathrm{kg} / \mathrm{min})(\mathrm{r}=-0.418, \mathrm{p}<0.01)$. CONCLUSION: The results suggest the striking effect of body fat on cardiorespiratory functions. Excessive amount of body fat exerts an unfavourable burden on cardiac function and oxygen uptake by working muscles. In our study WHR has significant negative correlation with $\mathrm{VO}_{2} \max$ and WHR can be used in clinical settings to estimate cardiorespiratory fitness as it is a rapid and inexpensive method.

KEY WORDS: $\mathrm{VO}_{2} \max , \mathrm{QCT}, \mathrm{WHR}$, cardiorespiratory fitness.

INTRODUCTION: The prevalence of cardiovascular disease has increased substantially over the past few decades in younger population. ${ }^{1}$ Numerous clinical investigations have established a strong association between low cardiorespiratory fitness and mortality ${ }^{2,3}$. Unfavourable cardiovascular risk profiles are found in youth with low levels of cardiovascular fitness and high percentage of body fat. Numerous risk factors for CVD, including hypertension, diabetes and hypercholesterolemia are suspected to be influenced by fitness and these factors may mediate the association between low cardiorespiratory fitness and mortality 4 .

$\mathrm{VO}_{2} \mathrm{max}$ is internationally accepted parameter to evaluate cardiovascular fitness ${ }^{5}$. The use of direct method to measure $\mathrm{VO}_{2}$ max is restricted because of its exhausting and difficult experimental protocol and absence of well equipped laboratory. Earlier studies have established the use of Queen's college step test to predict $\mathrm{VO}_{2}$ max indirectly ${ }^{6}$.

Obesity is an independent risk factor for cardiovascular disease. Obesity can be assessed in several ways. Measurement of waist to hip ratio is used to reflect body fat in clinical settings as these measurements provide rapid and cheap way to estimate body fat ${ }^{7}$. Earlier studies have demonstrated the importance of low cardiorespiratory fitness in young adulthood as a factor for developing cardiovascular comorbidities later in middle age ${ }^{8}$. This study is designed to evaluate cardiorespiratory fitness in terms of $\mathrm{VO}_{2} \mathrm{max}$ and its relation with waist-to-hip ratio in young healthy male subjects. 


\section{ORIGINAL ARTICLE}

METHODS AND MATERIALS: The study group comprises of 100 young healthy males in the age group of 18-25 yrs. The present study was conducted in The Department of Physiology, Sri Siddhartha Medical College, Tumkur. Ethical clearance for the study protocol was obtained from institutional ethical committee. Subject's clinical history and details were taken according to the standard proforma. Informed written consent was taken from all subjects in the study.

Subjects with history of cardiac disease, lung disease, Smoking history, those on regular medications affecting cardiovascular and respiratory system and those who are undergoing any physical conditioning programme were excluded from the study.

100 apparently healthy male subjects were selected for the study. The experimental protocol was fully explained to the participants to allay apprehension. The subjects were refrained from any energetic physical activity for 3 hours before the test.

Experimental design: Data was collected by calculating waist to hip ratio and assessing $\mathrm{VO}_{2}$ max indirectly by Queen's college step test. Waist and hip circumference were measured after asking the subject to remove the garments of the upper half of the body, waist circumference was taken at the lowest possible circumference at abdomen after normal expiration while the subject is standing with his feet together and arms by the side of the body. Hip circumference was taken as the maximum girth around the hip with minimum clothes. The waist-to-hip ratio is calculated using the below formula9.

WHR= Waist circumference $(\mathrm{cm})$

Hip circumference $(\mathrm{cm})$

Step test was performed using a stool of 16.25 inches $(41.30 \mathrm{cms})$ height. Stepping was done for a total duration of 3 minutes at the rate of 24 cycles per minute which was set by a stop watch. After completion of the exercise the subjects were asked to remain standing comfortably and carotid pulse rate was measured from $5^{\text {th }}$ to $20^{\text {th }}$ second of recovery period. This 15 second pulse rate is converted into beats per minute and $\mathrm{VO}_{2}$ max is predicted using the following equation ${ }^{10}$.

$\mathrm{VO}_{2} \max =111.33-(0.42 \times$ pulse rate in beats per minute $)$

Statistical analysis: Cardiorespiratory fitness in terms of $\mathrm{VO}_{2}$ max was evaluated and then the effect of WHR on cardiorespiratory fitness was studied in 100 young healthy males. Data was statistically analysed by Pearson's correlation and results are shown in tables and graphs. The statistical software SPSS 15.0 was used .The data profile of subjects including name, age, waist circumference, hip circumference, waist-to-hip ratio, QCT pulse rate and $\mathrm{VO}_{2}$ max with their mean and standard deviation are shown in table 1.

RESULTS: There was a significant negative correlation between WHR and $\mathrm{VO}_{2} \max (\mathrm{ml} / \mathrm{kg} / \mathrm{min})(\mathrm{r}=$ $-0.418, \mathrm{p}<0.01)$.

\begin{tabular}{|c|c|c|}
\hline Parameters & Mean & Standard Deviation \\
\hline Age (yrs) & 19.06 & 1.26985 \\
\hline Waist (cm) & 81.2 & 10.65056 \\
\hline Hip (cm) & 93.49 & 8.00946 \\
\hline WHR & 0.865999 & 0.05170 \\
\hline QCT pulse rate & 170.04 & 16.08558 \\
\hline $\mathrm{VO}_{2} \mathrm{max}(\mathrm{ml} / \mathrm{kg} / \mathrm{min})$ & 39.9132 & 6.75594 \\
\hline \multicolumn{2}{|c|}{ Table 1. Profile of the study group. } \\
\hline
\end{tabular}




\section{ORIGINAL ARTICLE}

\begin{tabular}{|c|c|c|}
\hline \multicolumn{2}{|c|}{ Variable } & $\mathrm{VO}_{2} \max$ \\
\hline \multirow{3}{*}{ WHR } & $\mathrm{r}$ & $-0.418^{* *}$ \\
\cline { 2 - 3 } & $\mathrm{p}$ & $<0.01^{*}$ \\
\hline
\end{tabular}

Table 2. Correlation between $\mathrm{VO}_{2} \max$ and WHR.

*--Significant

**--the correlation between WHR and $\mathrm{VO}_{2} \max$ is negative .i.e., as WHR increases the $\mathrm{VO}_{2} \max$ is decreasing and vice versa.

DISCUSSION: This study was done to study the effect of WHR on cardiorespiratory fitness. Cardiorespiratory fitness was evaluated in 100 young healthy male subjects in terms of $\mathrm{VO}_{2}$ max and then WHR was correlated with cardiorespiratory fitness.

$\mathrm{VO}_{2} \mathrm{max}$ is a measure of the functional limit of cardiorespiratory system and single most valid index of maximal exercise capacity. The absolute value of $\mathrm{VO}_{2}$ max is one of the indices of an individual's cardiorespiratory fitness to transport oxygen to working muscles. Earlier studies have used $\mathrm{VO}_{2}$ max values in $\mathrm{ml} / \mathrm{kg} / \mathrm{min}$ to examine the performance of cardiorespiratory fitness.

Excessive amount of body fat exerts an unfavorable burden as well as hindering action towards cardiac function, particularly during exhaustive exercise, when excessive hyperactive body musculature fails to uptake sufficient amount of oxygen due to deposition of proportionately high amount of fat mass. Loss of weight during weight reduction program of obese increased their $\mathrm{VO}_{2} \mathrm{max}(\mathrm{ml} / \mathrm{kg} / \mathrm{min})$ due to withdrawal of fat induced inhibitory action towards oxygen utilization by body musculature. ${ }^{11}$

Elevated myocardial oxidative stress has been reported in patients with obesity. In obese individuals there is increase in type II muscle fibers and decrease in type I muscle fibers which may have important effect on reduced oxygen uptake. Overweight subjects have much greater increase in sympathetic nerve firing rate than normal subjects. Obesity is said to produce a state of chronic volume overload because heart is required to continuously circulate blood through the large and relatively low resistance depot of adipose tissue. Increased preload and stroke volume are associated with hypertension. Combination of overweight and hypertension leads to thickening of ventricular wall and larger heart volume and thus a greater likelihood of cardiac failure ${ }^{12}$.

Waist circumference was developed initially as a simpler measure-and a potentially better indicator of health risk than body mass index-to use in health promotion. Waist circumference alone, however, does not give a better prediction of visceral and total fat and of disease risks than waist to hip ratio. Waist circumference is minimally related to height, so correction for height (as in waist to height ratio) does not improve its relation with intraabdominal fat ${ }^{13}$.

People with a large waist are many times more at risk of ill health, including features of metabolic syndrome (such as diabetes, hypertension and dyslipidemia) as well as shortness of breath and poor quality of life ${ }^{13}$. These increased risks also apply in people whose body mass index is normal but who have a large waist. During weight loss, each kilogram of weight loss is equivalent to a reduction of $1 \mathrm{~cm}$ in waist circumference ${ }^{14}$.

Hip circumference does have a relation to health and disease, but in an inverse way, such that a relatively large hip circumference is associated with lower risks of diabetes and coronary heart disease. This is probably because hip circumference reflects muscle mass, which is reduced in 


\section{ORIGINAL ARTICLE}

type 2 diabetes and inactivity. Hip circumference alone, however, does not give a better prediction of visceral and total fat and of disease risks than waist to hip ratio ${ }^{15}$.

Waist to hip ratio was introduced mainly as a result of Swedish research-on the assumption that it would predict fat distribution better than waist circumference alone. Subsequent research proved it. A recent report from the international Inter heart study proposed waist to hip ratio as the best adiposity risk marker for acute myocardial infarction. This study was a case-control study 15 .

Welch et al reported that $\mathrm{VO}_{2} \max$ was significantly decreased in overweight individuals when fat mass was taken into account which suggests the possibility of deconditioning and changes in cardiorespiratory function in severely overweight individuals ${ }^{16}$.Watanabe $\mathrm{K}$ et al reported that obesity accentuates exercise intolerance and low aerobic capacity ${ }^{17}$. Similar results were observed by Rowland TW et $\mathrm{al}^{18}$.

Norman et al studied influence of excess adiposity on exercise fitness and performance in overweight children and adolescents and found that overweight and non-over weight adolescents had similar absolute cardiorespiratory fitness but the functional impairment was significantly associated with increased energy demands needed to move their excess bodyweight ${ }^{19}$. Several previous studies have found no significant differences in $\mathrm{VO}_{2}$ max between obese and non obese.

In this study we found that there was a significant negative correlation between WHR and $\mathrm{VO}_{2} \max (\mathrm{ml} / \mathrm{kg} / \mathrm{min})(\mathrm{r}=-0.418, \mathrm{p}<0.01)$.

CONCLUSIONS: There was a significant negative correlation between WHR and $\mathrm{VO}_{2}$ max $(\mathrm{ml} / \mathrm{kg} / \mathrm{min})$. This suggests the effect of body fat on cardiorespiratory functions. These findings demonstrate the importance of low cardiorespiratory fitness in young adults with increased body fat is a factor for developing cardiovascular comorbidities later in middle age. Queen's college step Test is a valid method for the estimation of $\mathrm{VO}_{2}$ max in young males. WHR can be used in clinical settings to estimate cardiorespiratory fitness as it is a rapid and inexpensive methods. Additional study including detailed measurement of cardiac function is needed to clarify whether cardiac impairment (or initial stages of impairment) exists. Given the current obesity trend and observations of a decline in daily energy expenditure among the people, improving cardiorespiratory fitness in young men by engaging in physical activities is important.

\section{REFERENCES:}

1. Buffart M, Roebroeck ME, Rol M, Stam HJ. Triad of physical activity, aerobic fitness and obesity in adolescents and young adults with myelomeningocele. J Rehabil Med 2008; 40:705.

2. Lee CD, Blair SN. Cardiorespiratory fitness and smoking related and total cancer mortality in men. Med Sci Sports Exerc 2002; 34:735-9.

3. Lee CD, Blair SN. Cardiorespiratory fitness and stroke mortality in men. Med Sci Sports Exerc 2002; 34:592-5.

4. Kraus WE, Houmard JA, Duscha BD. Effects of the amount and intensity of exercise on lipoproteins. N Engl J Med 2002; 347:1483-92.

5. Chatterjee S, Chatterjee P, Bandopadhyay A. Validity of Queen's College Step Test for estimation of maximal oxygen uptake in female students. Indian J Med Res 2005; 121:32 -5. 


\section{ORIGINAL ARTICLE}

6. Chatterjee S, Chatterjee P, Bandopadhyay A. Validity of Queen's College step test for use with young Indian men Br J Sports Med 2004;38:289-91.

7. Thang SH, Naveed S, Mike L. Assessment of obesity and its clinical implications. BMJ 2006; 333:695-8.

8. Carnethon MR, Gidding SS, Nehgme B, Sidney S, Jacobs DR, Lin K. Cardiorespiratory fitness in young adulthood and the development of cardiovascular disease risk factors. JAMA 2003; 290:3092-100.

9. McArdle WD, Katch FI and Katch VL. Essentials of Exercise Physiology: Body composition, obesity and weight control. $3^{\text {rd }}$ ed. Philadelphia: Lippincott Williams \& Wilkins; 2005:558-67.

10. Koley S. Association of cardio respiratory fitness, Body composition and Blood pressure in collegiate population of Amritsar, Punjab, India. ISPUB 2007; 1:1.

11. Rocchini AP, Bray GA, Bouchard C, James WP. Handbook of obesity: Obesity and blood pressure regulation. $2^{\text {nd }}$ ed. New York: Marcel Dekker; 2004:873-97.

12. Salvadori A, Fanari P, Fontana M, Buontempi L, Baudo S. Oxygen uptake and cardiac performance in obese and normal subjects during exercise. Respiration 1999; 66:25-33.

13. Han TS, Lean ME, Seidell JC. Waist circumference remains useful predictor of coronary heart disease BMJ 1996; 312:1227-8.

14. Lean ME, Han TS, Morrison CE. Waist circumference as a measure for indicating need for weight management. BMJ 1995; 311:158-61.

15. Lissner L, Bjorkelund C, Heitmann BL, Seidell JC, Bengtson C. Larger hip circumference independently predicts health and longevity in a Swedish female cohort. Obese Res 2001; 9:644-6.

16. Welsh BE, Rieneau RP, Crisp CE, Isenstein RS. Relationship of maximal oxygen consumption to various components of body composition. J Appl Physiol 1958; 12: 395-8.

17. Watanabe K, Nakadomo F, Maeda K. Relationship between body composition and cardiorespiratory fitness in Japanese junior high school boys and girls. Ann Physiol Anthropol 1994; 13(4):167-74.

18. Rowland TW. Effects of obesity on aerobic fitness in adolescent females. Am J Dis child 1991; 145(7):764-8.

19. Norman AC, Drinkard B, Jennifer R, Ghorbani BS, Lisa BY, Jack A. Influence of excess adiposity on exercise fitness and performance in overweight children and adolescents. Pediatrics 2005; 115(6):600-96. 


\section{ORIGINAL ARTICLE}

\section{AUTHORS:}

1. Vivek P.

2. Thejaswini K.O.

3. Kavitha B.S.

\section{PARTICULARS OF CONTRIBUTORS:}

1. Assistant Professor, Department of Physiology, Sri Siddhartha Medical College \& Hospital, Tumkur, Karnataka, India.

2. Associate Professor, Department of Physiology, Sri Siddhartha Medical College \& Hospital, Tumkur, Karnataka, India.

3. Assistant Professor, Department of Physiology, Sri Siddhartha Medical College \& Hospital, Tumkur, Karnataka, India.

\section{NAME ADDRESS EMAIL ID OF THE CORRESPONDING AUTHOR:}

Dr. Vivek P, S/o. Parabramhachari V.S, "Sahrudayi", Behind Vivekananda School, $7^{\text {th }}$ Cross, Vidyanagar, Tumkur, Karnataka, India.

Email-vivek_p07@yahoo.co.in

Date of Submission: 10/09/2013. Date of Peer Review: 11/09/2013. Date of Acceptance: 25/09/2013. Date of Publishing: 01/10/2013. 